\title{
Rhetorical Variation of RA Abstracts between Experts and Chinese Undergraduates
}

\author{
Y. L. WANG \\ Fuyang Teachers' College, Fuyang, Anhui, China
}

\begin{abstract}
The study focused on the rhetorical variation of abstracts written by experts and Chinese undergraduates by investigating 60 RA abstracts in applied linguistics. Santos' (1996) 5-move model was adopted as the analytical framework. The results showed that abstracts by the two groups of writers shared Move 2, 3 and 4 as conventional. However, the move pattern did vary a lot among them. With regard to verb tense, despite the similar tendency of using present tense in Move 1,2 and 5, there were great differences in all the five moves in terms of occurrence frequency. The findings have significant pedagogical implications for novice writers' abstracting in applied linguistics.
\end{abstract}

KEYWORD: Abstracting; RA; Rhetorical Structure; Authorial Variation

\section{INTRODUCTION}

Due to the regular writing pattern and decisive role in the publishing, citation and retrieval of any RA, abstracts have received considerable attention of researchers in academic community, especially those non-native English speaking writers who are in pursuit of international recognition. For inexperienced academic beginners, such as Chinese undergraduates, it is much more challenging to write a good English abstract to sell their research successfully to potential readers. Previous studies of RA abstracts can be generally classified into the category of rhetorical organization (e.g. Cross \& Oppenheim 2006, Hyland 2004, Lau 2004, Martin 2003, Pho 2008, Santos 1996, Swales \& Feak 2009) and linguistic features (e.g. Hu \& Cao 2011, Hyland $\&$ Tse 2005) within or across the discipline of medicine, biology, psychology, applied linguistics etc. However, most of these researches, with an aim to detect the general rhetorical structure and its linguistic realizations, focused on the exploration of experts' abstracts. Few studies on undergraduates' abstracting have been published. In an attempt to shed lights on undergraduates' abstracting practices, this study seeks to explore the rhetorical variation of verb tense among the transitions of moves via structural analysis of the thesis abstracts written by Chinese undergraduates and the published RA abstracts written by experts.

\section{LITERATURE REVIEW}

Researches on rhetorical patterns of RA abstracts tend to take move as the basic analytical unit. First mooted by Swales, a move "......is considered as a genre stage which has a particular, minor communicative purpose to fulfill, which in turn serves the major communicative purpose of the genre" (Santos 1996: 485). The systemic interaction among moves results in a particular sequence of moves in abstracts. Among the existing move structure models for abstracting, Bhatia's (1993) 4move model, Santos' (1996) 5-move model, and Hyland's (2002) 5-move model are the preferred ones. While regarding the establishment of the structural organization of abstracts in applied linguistics, Santos was probably the first pioneer in this field. Based on an in-depth examination on 94 applied linguistic abstracts, Santos (1996) put forward a 5-move pattern for abstracts. It was elaborated in Table 1 below.

With regard to move structure analysis, Santos found that almost all the 94 examined abstracts had Moves 2 and Move 3, about $80 \%$ contained Move 4, about $53 \%$ and $43 \%$ included Move 5 and Move 1 respectively. Thus, it can be inferred that Move 2, 3 and 4 tend to be regarded as conventional in abstracts of applied linguistics. Similar findings were later revealed by Pho (2008). Pho's study showed that all the 20 abstracts in applied linguistics involved in the research contained Moves 2, 3 and 4, $80 \%$ of the abstracts had Move 5, and only $45 \%$ included Move 1. 
Table 1. Santos' (1996) framework for abstract analysis

\begin{tabular}{|l|l|l|}
\hline Moves & Function/Description & $\begin{array}{l}\text { Question } \\
\text { asked }\end{array}$ \\
\hline $\begin{array}{l}\text { Move 1: } \\
\text { Situating the } \\
\text { Research <STR }>\end{array}$ & $\begin{array}{l}\text { Setting the scene for the } \\
\text { current research (topic } \\
\text { generalization) }\end{array}$ & $\begin{array}{l}\text { What has been } \\
\text { known about } \\
\text { the field/topic } \\
\text { of research? }\end{array}$ \\
\hline $\begin{array}{l}\text { Move 2: } \\
\text { Presenting the } \\
\text { research <PTR> }\end{array}$ & $\begin{array}{l}\text { Stating the purpose of the } \\
\text { study, research questions } \\
\text { and/or hypotheses }\end{array}$ & $\begin{array}{l}\text { What is the } \\
\text { study about? }\end{array}$ \\
\hline $\begin{array}{l}\text { Move 3: } \\
\text { Describing the } \\
\text { methodology } \\
<\text { DTM> }\end{array}$ & $\begin{array}{l}\text { Describing the materials, } \\
\text { subjects, variables, } \\
\text { procedures }\end{array}$ & $\begin{array}{l}\text { How was the } \\
\text { research } \\
\text { done? }\end{array}$ \\
\hline $\begin{array}{l}\text { Move 4: } \\
\text { Summarizing the } \\
\text { findings <STF }>\end{array}$ & $\begin{array}{l}\text { Reporting the main } \\
\text { findings of the study }\end{array}$ & $\begin{array}{l}\text { What did the } \\
\text { researcher } \\
\text { find? }\end{array}$ \\
\hline $\begin{array}{l}\text { Move 5: } \\
\text { Discussing the } \\
\text { research <DTR> }>\end{array}$ & $\begin{array}{l}\text { Interpreting the } \\
\text { results/findings and/or } \\
\text { giving recommendations, } \\
\text { implications/applications } \\
\text { of study }\end{array}$ & $\begin{array}{l}\text { What do the } \\
\text { results mean? } \\
\text { So what? }\end{array}$ \\
\hline
\end{tabular}

In respect of tense analysis in applied linguistics, many researches have been conducted after the study of Salager-Meyer (1992). Tseng (2011) examined the preferred pattern of verb tense of each move in 90 RA abstracts selected from three applied linguistic journals and revealed that the present tense usually occurred in the Background, Aim, Conclusion move, whereas the past tense was frequently found in the Method and Results move, which was generally in accordance with those of Santo's (1996) and Pho's (2008). However, the study of Suntara \& Usaha (2013) showed a preference for present tense over past tense in the Results move. Just as revealed by Swales and Feak (2004), "......there appears to be considerable disciplinary and individual tense variation with sentences dealing with results (283)", verb tense in abstracts is much more complex and needs to be further explored.

\section{METHODOLOGY}

\subsection{The construction of datasets}

A total of 30 RA abstracts published from 2011 to 2013 were selected randomly from TESOL Quarterly, a journal with a high impact factor in the field of applied linguistic, to form "Dataset 1", representing RA abstracts written by expert writers. And a total of 30 abstracts of theses for Bachelors' degree from 2011 to 2013 in a major Chinese university were collected randomly to form "Dataset 2", representing RA abstracts written by student writers. As for the thesis abstracts, in most cases, they are the final step in thesis production and are written without close supervision, hence, it is safe to conclude that they give the most accurate picture of students' academic writing competence. The corpus is approximately 14,400 words in total. For the sake of reliability of the research, the selection of all the abstracts was restricted within three factors. First, the length of the abstracts was controlled between 150-250 words. Second, the topic of the abstracts was narrowed in the discussion of EFL teaching. Thirdly, all the abstracts were selected out of empirical researches.

\subsection{Analysis of rhetorical structure}

A datasets were analyzed using Santos' (1996) model. The adoption of this analytical framework is partly due to the practicability of the model owing to the help of the list of questions asked in each move (see Table 1), and partially due to the usefulness of the model justified by previous researchers. The basic coding unit for the abstracts was a sentence, which was tagged with a move label. Given the condensed nature of an abstract and the empirical nature of all the researches involved in this study, move-embedding is predictable. Pho (2008) demonstrated that a sentence in an abstract can be responsible for two or more functions simultaneously, thus such a sentence is decoded into two or more moves. Therefore, if move embedding was found in the present study, the sentence would be tagged with two or more move labels. For example, in a sentence "Using the National Education Longitudinal Study of......, we present...... in postsecondary education", Move 3 DTM is embedded into Move 2 PTR by employing the expression "using ..." to show the research method.

\subsection{Analysis of verb tense}

Based on preparatory observation on the usage of verb tense in each move of the abstracts, this study focused on two most popular forms of verb tense: the present tense (including the present perfect tense) and the past tense. In order to highlight the preferred verb tense in each move of an applied linguistic abstract and the difference in verb tense usage between expert writers and student writers, the analysis took the procedure from a larger research project conducted by Tseng (2011).

\section{RESULTS AND DISCUSSION}

\subsection{Move frequency}

The result of rhetorical moves occurrence in Dataset1 \& Dataset 2 were illustrated in Table 2.

Table 2. The occurrence of rhetorical moves in Dataset $1 \&$ Dataset 2

\begin{tabular}{llrrrr}
\hline Datasets & Move 1 & Move 2 & Move 3 & Move 4 & Move 5 \\
\hline Dateset 1 & $56.70 \%$ & $100.00 \%$ & $93.30 \%$ & $76.70 \%$ & $63.30 \%$ \\
Dataset 2 & $100.00 \%$ & $73.30 \%$ & $70.00 \%$ & $60.00 \%$ & $46.70 \%$ \\
\hline
\end{tabular}


Table 2 above showed that in Dataset 1, Move 2 (100\%) ranked first, followed by Move 3 (93.3\%). Comparatively, Move $1(56.7 \%)$ had the lowest frequency, leaving Move $4(76.7 \%)$ and Move 5 $(63.3 \%)$ in the middle of the continuum. As for Dataset 2, Move 1, with $100 \%$ occurrence, was on the top of the list, followed by Move 2 (73.3\%). Move $3(70 \%)$ recorded third, followed by Move 4 (60\%), leaving Move 5 at the bottom of the list with an occurrence of $46.7 \%$.

Based on the cut-off of a $60 \%$ occurrence rate as suggested by Kanoksilapatham (2005), the results above indicated that Move 2, Move 3, Move 4 and Move 5 in Dataset 1 were conventional and Move 1 was optional, which were in line with the findings of Suntara \& Usaha (2013). In Dataset 2, however, Move 1, Move 2, Move 3 and Move 4 were found to be conventional and Move 5 was optional. From the results above, it could be concluded that Move 2, Move 3 and Move 4 were conventional in both the expert and student writers' abstracts. As far as the most frequently used move was concerned, the student writers had a unanimous preference for Move 1, which, however, was recorded as optional with the lowest frequency of occurrence $(56.7 \%)$ for the expert writers. Even though Hyland (2004) suggested that there was an increasing trend of the appearance of Introduction move in abstracts, yet the totally indispensable role of the Move $1(100 \%)$ in student writers' abstracts was abnormal. The great disparity existing between the student and expert writers probably lie in the fact that the student writers, due to inadequate command of knowledge and attainment of confidence, tended to use two or more sentences to situate their researches. And a closer look at student writers' wording of Move 1 revealed they are inadequate in making generalizations. Besides, student writers' incompetence in relating research results into teaching practices probably provided some answers to the conventional Move 5 being perceived as optional and the least frequent one in abstracts.

\subsection{Move pattern}

The findings showed that the expert writers favored the move patterns of PTR-DTM-STF-DTR (30\%), STR-PTR-DTM-STF-DTR (30\%), and PTR-DTMSTF (10\%), which accorded with the results of Suntara \& Usaha (2013). In contrast, the most frequent patterns adopted by the student writers were STR-PTR-STF-DTR and STR-PTR-DTM-STF, each only accounting for $13.3 \%$ respectively. Meanwhile, the most frequently used move pattern in the expert writers' abstracts - STR-PTR-DTM-STF-DTR - was recorded at $10 \%$ as compared to $30 \%$ with the expert writers. The irregular, arbitrary move pattern employed by the student writers indicated the current Chinese undergraduates severe shortage of knowledge on the structural organization of abstracts.

\subsection{Verb tense of moves}

The frequency of the verb tense in each move of the abstracts was illustrated in Table 3.

Table 3. Results of verb tense frequency of each move

\begin{tabular}{|c|c|c|c|c|c|}
\hline & & $\mathrm{Da}$ & et 1 & & set 2 \\
\hline \multirow{3}{*}{$\begin{array}{l}\text { Move 1: } \\
\text { STR }\end{array}$} & Present & 16 & $94 \%$ & 23 & $77 \%$ \\
\hline & past & 0 & $0 \%$ & 0 & $0 \%$ \\
\hline & Present + Past & 1 & $6 \%$ & 7 & $23 \%$ \\
\hline \multirow{3}{*}{$\begin{array}{l}\text { Move 2: } \\
\text { PTR }\end{array}$} & Present & 18 & $60 \%$ & 22 & $100 \%$ \\
\hline & past & 10 & $33 \%$ & 0 & $0 \%$ \\
\hline & Present + Past & 2 & $7 \%$ & 0 & $0 \%$ \\
\hline \multirow{3}{*}{$\begin{array}{l}\text { Move 3: } \\
\text { DTM }\end{array}$} & Present & 8 & $35 \%$ & 12 & $100 \%$ \\
\hline & past & 14 & $61 \%$ & 0 & $0 \%$ \\
\hline & Present + Past & 1 & $4 \%$ & 0 & $0 \%$ \\
\hline \multirow{3}{*}{$\begin{array}{l}\text { Move 4: } \\
\text { SIF }\end{array}$} & Present & 6 & $27 \%$ & 17 & $100 \%$ \\
\hline & past & 4 & $18 \%$ & 0 & $0 \%$ \\
\hline & Present + Past & 12 & $55 \%$ & 0 & $0 \%$ \\
\hline \multirow{3}{*}{$\begin{array}{l}\text { Move 5: } \\
\text { DTR }\end{array}$} & Present & 16 & $89 \%$ & 13 & $100 \%$ \\
\hline & past & 0 & $0 \%$ & 0 & $0 \%$ \\
\hline & Present + Past & 2 & $11 \%$ & 0 & $0 \%$ \\
\hline
\end{tabular}

The findings revealed that in Dataset 1 , the preferred verb tense of Move 1,2 and 5 was present tense. Past tense was most frequently used in Move 3. And Move 4 was more likely to be presented in the combination of present tense and past tense. These results, except for the preferred verb tense of Move 4, were generally in line with those of Tseng (2011) and Suntara \& Usaha (2013). In Tseng's (2011) study, Move 4 was more frequently $(82 \%)$ presented in past tense while in the present research, more than half $(55 \%)$ of the Move 4 were realized in the mixing of present tense and past tense. The difference might be due to the fact that the data involved in the present study and Tseng's study were selected from different periods of the Journal TESOL Quarterly, 2011-2013 and 2005-2007 respectively. This may suggest that abstracting practices vary diachronically even within the same journal. Pho (2008) interpreted that verb tense used in the result section functions differently. Generally, past tense was adopted to help establish the image of being objective in reporting the research findings, while present tense was used mainly for generalizing beyond the study results. In this study, the expert writers' preference of present tense in the main clause and past tense in the subordinate clause could be perceived as an intention to report the results objectively and generalize the results to be widely accepted, demonstrating authorial stance in disseminating academic findings. 
With regard to the results of Dataset 2, the predominant preference for present tense was apparent from the absolute $100 \%$ dependence on it in Move 2, 3, 4 and 5. A closer look at all the 30 abstracts in Dataset 2 revealed that $40 \%$ did not present study methods in the so-called informative abstracts, and among the $60 \%$ with an description of research methods, $17 \%$ preferred to embed the DTM move into the PTR or STF move and $10 \%$ even irrationally chose the future tense to describe the methods adopted in their accomplished researches. According to Santos (1996), the use of present tense in the STF move indicated that the research results generated indisputable knowledge while the selection of past tense signified a narrower claim of the results. Taking the academic immaturity of undergraduates, the student writers' total reliance on present tense to summarize their findings may be understood as an arbitrary generalization. These widely divergent practices revealed undergraduates' awkward inflexibility and incapability in handling verb tense in abstracting, and hence an urgent demand for the instruction and acquisition of verb tense in their academic courses.

\section{CONCLUSION}

The results of the research were summarized in the following three points. First, abstracts written by the two groups of writers shared Move 2, 3 and 4 as conventional, although the total occurrences of the three moves were higher in the expert writers' abstracts. For the expert writers, move 5 was conventional and move 1 was optional, but it was completely reversed with Chinese undergraduates. Second, the move pattern did vary a lot among these two groups of writers. Although both groups favored STR-PTR-DTM-STF-DTR, the ratio was 3 to 1 between expert and student writers. Third, with regard to verb tense, despite the similar tendency of using present tense in Move 1, 2 and 5, there were great differences in all the five moves of the abstracts in terms of occurrence frequency.

The findings have important pedagogical implications. As evolving writers, undergraduates need to know how to structure an abstract in their discipline and how to realize the structure in verb tense. Knowledge concerning the rhetorical structure of RA abstracts should be explicitly imparted to undergraduates in the advanced writing classes to help ease their process of abstracting as well as to promote their academic career. Although the research has highlighted the rhetorical variation of abstracts in applied linguistics, it has limitations in the volume and types of data involved. Larger amount of data from diversified sources on theoretical studies are expected to be explored to give more pictures of abstracting in applied linguistics.

\section{ACKNOWLEDGEMENTS}

This work was financially supported by Fuyang Teachers' College under the projects 2013FSSK01ZD，2013JCJS07，2013JXTD07 and National Foreign Language Education Foundation under the projects ZGWYJYJJ2014A61.

\section{REFERENCES}

[1] Bhatia,V.K. (1993). Analysing Genre: Language Use in Professional Settings. London: Longman.

[2] Cross, C., \& Oppenheim, C. (2006). A genre analysis of scientific abstracts. Journal of Documentation, 62(4), 428446.

[3] Hu, G., \& Cao, F. (2011). Hedging and boosting in abstracts of applied linguistics articles: A comparative study of English-and Chinese-medium journals. Journal of pragmatics, 43(11), 2795-2809.

[4] Hyland, K. (2002). Teaching and researching writing. Harlow, England: Pearson Education.

[5] Hyland, K. (2004). Disciplinary discourses: Social interactions in academic writing. Ann Arbor: University of Michigan Press.

[6] Hyland, K., \& Tse, P. (2005). Hooking the reader: A corpus study of evaluative that in abstracts. English for Specific Purposes, 24(2), 123-139.

[7] Kanoksilapatham, B. (2005). Rhetorical studies of biochemistry research articles. English for Specific Purposes, 24(3), 269-292.

[8] Lau, H. H. (2004). The structure of academic journal abstracts written by Taiwanese $\mathrm{PhD}$ students. Taiwan Journal of TESOL, 1(1), 1-25.

[9] Martin, P. M. (2003). A genre analysis of English and Spanish research paper abstracts in experimental social sciences. English for Specific Purposes 22(1), 25-43.

[10] Pho, P. D. (2008). Research article abstracts in applied linguistics and educational technology: a study of linguistic realizations of rhetorical structure and authorial stance. Discourse Studies, 10(2), 231-250.

[11] Salager-Meyer, F. (1992). A text-type and move analysis study of verb tense and modality distribution in medical English abstracts. English for Specific Purposes, 11(2), 93-113.

[12] Santos, M. B. D. (1996). The text organization of research papers abstracts in applied linguistics. Text, 16(4), 481499.

[13] Suntara, W., \& Usaha, S. (2013). Research Article Abstracts in Two Related Disciplines: Rhetorical Variation between Linguistics and Applied Linguistics. English Language Teaching, 6(2), 84-89.

[14] Swales, J. M., \& Feak, C. B. (2004). Academic writing for graduate students: Essential tasks and skills (Vol. 1). Ann Arbor, MI: University of Michigan Press.

[15] Swales, J. M., \& Feak, C. B. (2009). Abstracts and the Writing of Abstracts (Vol. 1). Michigan: University of Michigan Press.

[16] Tseng, F. P. (2011). Analyses of move structure and verb tense of research article abstracts in applied linguistics journals. International Journal of English Linguistics, 1(2), 27-39. 